\title{
Optimal Selection of Radiotherapy as Part of a Multimodal Approach for Hepatocellular Carcinoma
}

\author{
Hong In Yoon Jinsil Seong \\ Department of Radiation Oncology, Yonsei Cancer Center, Yonsei University Health System, Seoul, \\ Republic of Korea
}

\section{Key Words}

Hepatocellular carcinoma · Multimodal approach · Radiotherapy

\begin{abstract}
A multimodal approach to treatment is a basic oncologic principle with proven survival benefits for most cancer types. However, existing guidelines recommend single modalities for treating each stage of hepatocellular carcinoma (HCC). Nonetheless, multimodal approaches can be considered for HCC, depending on the characteristics of the disease in individual cases. Radiotherapy (RT), an effective local modality, is a critical element of most multimodal approaches. Improved RTtechnology and increased understanding of the tolerance of the liver to radiation have contributed to the popularity of RT for treating liver tumors in clinical practice. Consequently, numerous reports have described the effects of RT on liver cancer, despite a lack of stringent evidence for its benefits. RT can be delivered using various technologies and approaches, which may be the source of some confusion. For example, high-dose ablative RT can be curative on its own, or high-dose ablative or conventional RT can complement other treatments such as radiofrequency ablation and transarterial chemoembolization. Combinations of systemic agents and RT can also be applied. This review discusses the optimal selection of RT as part of a multimodal approach for HCC.
\end{abstract}

Copyright (C) 2016 S. Karger AG, Basel 


\section{Introduction}

Multimodal treatment is a basic oncologic principle that incorporates surgery, radiotherapy (RT), and chemotherapy [1,2]. It has proven survival benefits for most cancer types [3-5]. However, a range of single modalities is generally recommended for treating each stage of hepatocellular carcinoma (HCC). Nevertheless, the multimodal approach may also be considered according to the disease characteristics in individual cases.

The Barcelona Clinic Liver Cancer (BCLC) staging system is most commonly used to stage HCC. It is endorsed by the American Association for the Study of Liver Diseases and the European Association for the Study of the Liver. Guidelines based on the BCLC staging system recommend a single modality as the standard treatment for each stage [6]. However, single-modality treatment frequently results in local or distant failure in the treatment of non-early-stage HCCs, which constitute the majority of cases [7].

The National Comprehensive Cancer Network (NCCN) guidelines recommend externalbeam RT as a locoregional therapy for potentially resectable and unresectable HCC patients [8]. The Korean Liver Cancer Study Group (KLCSG) guidelines, established in 2003 [9] and updated in 2014 [10], recommend RT depending on the stage of HCC [10]. Both the 2003 and 2014 KLCSG guidelines support RT for the treatment of HCC because RT can exert an independent ablative effect and generally complements other treatments.

This article reviews the usage of RT in HCC treatment and discusses the clinical application of RT according to the 2014 KLCSG guidelines. Ongoing clinical trials and the optimal selection of RT as a part of multimodal approaches to HCC treatment are also discussed.

\section{Beneficial Effects of RT against HCC}

RT was previously not indicated for HCC because of the low tolerance of the liver to radiation. However, since Emami et al. estimated the tolerance dose for a 5\% incidence of radiation-induced liver disease (RILD) in 5 years (TD5/5) after one-third liver irradiation to be 50 Gy at 1.8-2 Gy/fraction [11], several studies have confirmed high levels of tolerance of focal liver irradiation. For one-third of the liver irradiated, the estimated TD5/5 value is reportedly $>40$ Gy $[12,13]$. A group from the University of Michigan also proposed that the delivery of $>100$ Gy may be possible without high risk of RILD if the effective irradiated liver volume is $<25 \%$ [14]. Furthermore, technological progress in RT from three-dimensional conformal RT (3D-CRT) to intensity-modulated RT (IMRT), image-guided RT, and stereotactic body RT (SBRT) has enabled the delivery of high-precision RT for local HCC accompanied by minimal doses to the normal liver volume without inducing RILD [15-30].

RT for HCC can improve therapeutic outcomes through excellent local control, downstaging, conversion from unresectable to resectable status, and inhibition of intrahepatic metastasis. Excellent local control rates produced by SBRT can lead to favorable survival outcomes without severe radiation-induced toxicities, including 2-year overall survival (OS) rates of $53-61 \%$, response rates of $45-63 \%$, and grade 3 hepatic toxicity incidence rates of $6.5-16 \%[15,16,31,32]$. Local RT combined with systemic chemotherapy can result in downstaging and can subsequently convert the tumor status from unresectable to resectable. Downstaging may allow some patients to undergo radical resection, thereby improving long-term survival [33]. Local RT for major tumors and portal vein tumor thrombosis (PVTT) may prevent rapid intrahepatic metastasis, an adverse prognostic factor that makes it difficult to determine the best treatment strategy [18]. Compared to 3D-CRT, using intensity-modulated image-guided RT (IG-IMRT) as an advanced technique to apply high-dose RT to the partial liver in locally advanced HCC patients with good performance status and good 
hepatic function reduces infield failure $(29.2 \%$ vs. $44.3 \%, \mathrm{p}=0.045)$ and improves survival (20 vs. 10 months, $\mathrm{p}<0.001$ ) [18]. These findings suggest that high-dose, high-precision RT may have survival benefits.

\section{RT According to Modified UICC TNM Stage}

Unlike the BCLC staging system, the Union for International Cancer Control (UICC) staging system is anatomically based, describing the disease according to the extent of the primary tumor $(\mathrm{T})$, regional lymph node involvement $(\mathrm{N})$, and the presence (or otherwise) of distant metastases (M) [34, 35]. The UICC system describes the primary tumor site based on whether it meets the following criteria: (1) number of tumors: solitary; (2) diameter of the largest tumor: no more than $2 \mathrm{~cm}$; and (3) no vascular or bile duct invasion. Stage T1 is defined as a primary tumor that fulfills all three criteria, T2 is a primary tumor that fulfills two of the three criteria, T3 is a primary tumor that fulfills one of the three criteria, and T4 is defined as a primary tumor that fulfills none of the criteria. Categories $\mathrm{N}$ and $\mathrm{M}$ describe regional lymph node involvement and distant metastasis, respectively. The modified UICC (mUICC) staging system categorizes HCC with T1, N0, and M0 as stage I and HCC with T2, N0, and M0 as stage II. T3NOM0 HCC patients are grouped as stage III. The mUICC staging system classifies T4N0M0 or N1M0 with any T stage as stage IVA and distant metastatic HCC as stage IVB. The fifth version of the mUICC staging system was adopted as the primary staging system for HCC by the KLCSG and National Cancer Centre (NCC) Korea in 2003.

The 2014 KLCSG guidelines recommend RT as an alternative for HCC patients unsuitable for surgical resection, radiofrequency ablation (RFA), ethanol injection, or transarterial chemoembolization (TACE) for mUICC stage I. For a single stage II HCC tumor $>2 \mathrm{~cm}$ without vascular/ductal invasion, RT is also an alternative option in patients unsuitable for surgical resection, RFA, TACE, or liver transplantation. For a single tumor $<2 \mathrm{~cm}$ with vascular invasion in stage II HCC, RT is one of the best therapeutic options. RT is also recommended as one of the best therapeutic options for a single stage III HCC $>2 \mathrm{~cm}$ with major vascular invasion [10].

\section{SBRT for mUICC Stage I/II HCC}

Curative therapies can improve survival in early-stage HCC patients. However, the risk of complications from local ablation increases in tumors located below the hepatic dome and adjacent to the main portal vein (PV). RT may be a feasible alternative for these patients, especially for those who are inoperable or refuse surgery. Local high-dose RT, including SBRT, can be an appropriate alternative definitive or salvage treatment [36-41] (table 1). A French prospective trial evaluated the feasibility and efficacy of high-dose 3D-CRT in cirrhotic patients with small HCC: 66 Gy was delivered in 33 fractions, resulting in a tumor response rate of $92 \%$ [39]. Bae et al. also investigated the tumor response and local control rates in patients who underwent salvage hypofractionated RT of 50 Gy in 10 fractions. They reviewed 20 patients with HCC $\leq 5 \mathrm{~cm}$ and no PVTT; the complete response (CR) and in-field control rates were $35 \%$ and $85 \%$, respectively [40]. Andolino et al. investigated the safety and efficacy of SBRT in 60 patients with primary, liver-confined HCC: the 2-year local control, progression-free survival (PFS) rate, and OS rate were 90\%, 48\%, and 67\%, respectively [36]. Andolino et al. thereby demonstrated that SBRT is a safe, effective, and noninvasive option for HCC $\leq 6 \mathrm{~cm}$ and that SBRT can be considered as bridging locoregional therapy to transplantation or definitive therapy in patients ineligible for transplantation. O'Connor et al. reported the safety and efficacy of SBRT as a bridge to transplantation for HCC [42]; patients underwent orthotopic liver transplantation after SBRT with a median time from SBRT to liver transplantation of 113 days 
(range: 8-794 days). The 5-year overall and disease-free survival rates were both 100\%, whereas the pathologic CR rate was $27 \%$. These results show that SBRT has clinical value as a bridging therapy to transplantation as part of a multimodal approach.

\section{Additional RT after Incomplete Response to TACE or RT for HCC Unfit for TACE in mUICC Stage II/III HCC \\ Patients diagnosed with stage II/III HCC can benefit from TACE [43]. However, TACE has} limitations, including vascular shunting, recanalization around the tumor capsule, and the development of multiple feeding vessels $[44,45]$. Although TACE is repeatedly performed to overcome these limitations, it commonly leads to outgrowth of HCCs refractory to TACE. RT can be useful as a complementary modality. TACE followed by RT is a feasible and effective complementary treatment for patients with incomplete necrosis after TACE [46-49] (table 2). A meta-analysis demonstrated that TACE in combination with RT significantly improves the 5 year-survival (odds ratio [OR]: 4.47, 95\% confidence interval [CI]: 2.08-9.61, $\mathrm{p}=0.0001$ ) and tumor CR (OR: $2.58,95 \% \mathrm{CI}: 1.64-4.06, \mathrm{p}=0.0001$ ) rates compared to TACE alone [50]. A recent prospective phase II multicenter study investigated the efficacy and toxicity of RT following an incomplete response to TACE [51]; 31 patients who still had viable tumors after no more than three courses of TACE were enrolled, whereas patients with main PV invasion were excluded. The primary endpoint was tumor response. A best objective infield response rate was achieved in $83.9 \%$ of patients, with $22.6 \%$ of patients achieving CR within 12 weeks of RT. The 2-year in-field PFS, PFS, and OS rates were 45.2\%, 29.0\%, and $61.3 \%$, respectively. These findings demonstrate that early application of 3D-CRT can be a practical option in multimodal approaches for patients with incomplete necrosis after TACE. For patients unsuitable for TACE therapy because of low vascularity or PVTT, RT could be also effective and feasible. Yoon et al. reported the clinical outcomes of patients after TACE for primary tumors who underwent RT for HCC with PVTT [52]: 3.6\% and 24.3\% of such patients achieved CR and partial response (PR), respectively. The 1- and 2-year survival rates were $42.5 \%$ and $22.8 \%$, respectively. The treatment response was an independent prognostic factor associated with OS (stable disease vs. CR and PR: hazard ratio [HR]: 3.06, 95\% CI: 2.38-3.94; $\mathrm{p}<0.01$ ) and treatment response was the most powerful predictor of survival in multivariate analysis (median survival of 19.4 months in responders and 7 months in nonresponders, $\mathrm{p}<0.001$ ) [52]. TACE plus RT resulted in significantly better OS than sorafenib only in advanced HCC (14.1 vs. 3.3 months before matching propensity scores and 8.9 vs. 3.1 months after matching propensity scores, $\mathrm{p}<0.001$ ] [53]. A recent study demonstrated that SBRT is feasible and can be effective for HCC patients who are refractory to, or unsuitable for, TACE, showing a CR rate of $32.8 \%$, a 2 -year in-field failure-free rate of $66.8 \%$, a median survival time (MST) of 20 months, and an RILD incidence rate of 9.4\% [54].

Concurrent Chemoradiation with Hepatic Arterial Infusion in mUICC Stage II/III HCC with Vascular Invasion

PVTT, the most detrimental feature of vascular invasion in HCC, has been a major obstacle to HCC management and limits the therapeutic options. However, PVTT is sensitive to RT, and the response rate ranges from $25 \%$ to $61.5 \%$ [52, 55-58]. Furthermore, RT can boost the treatment responses of tumors and PVTT, and thus likely bestows a survival benefit [33, 52, 59-62]. In one retrospective study, preoperative RT induced PVTT necrosis in 8 patients (53.3\%), and preoperative RT followed by surgery resulted in better outcomes than surgery alone for HCC with PVTT (5-year survival rate: $34.8 \%$ vs. $13.1 \%, p=0.0359$ ) [61]. Better PVTT responses to RT were significantly associated with better survival $[59,60]$. Several studies have indicated that hepatic arterial infusion concurrent chemoradiation (HAICCRT) may be a feasible and effective alternative for unresectable liver-confined HCC 

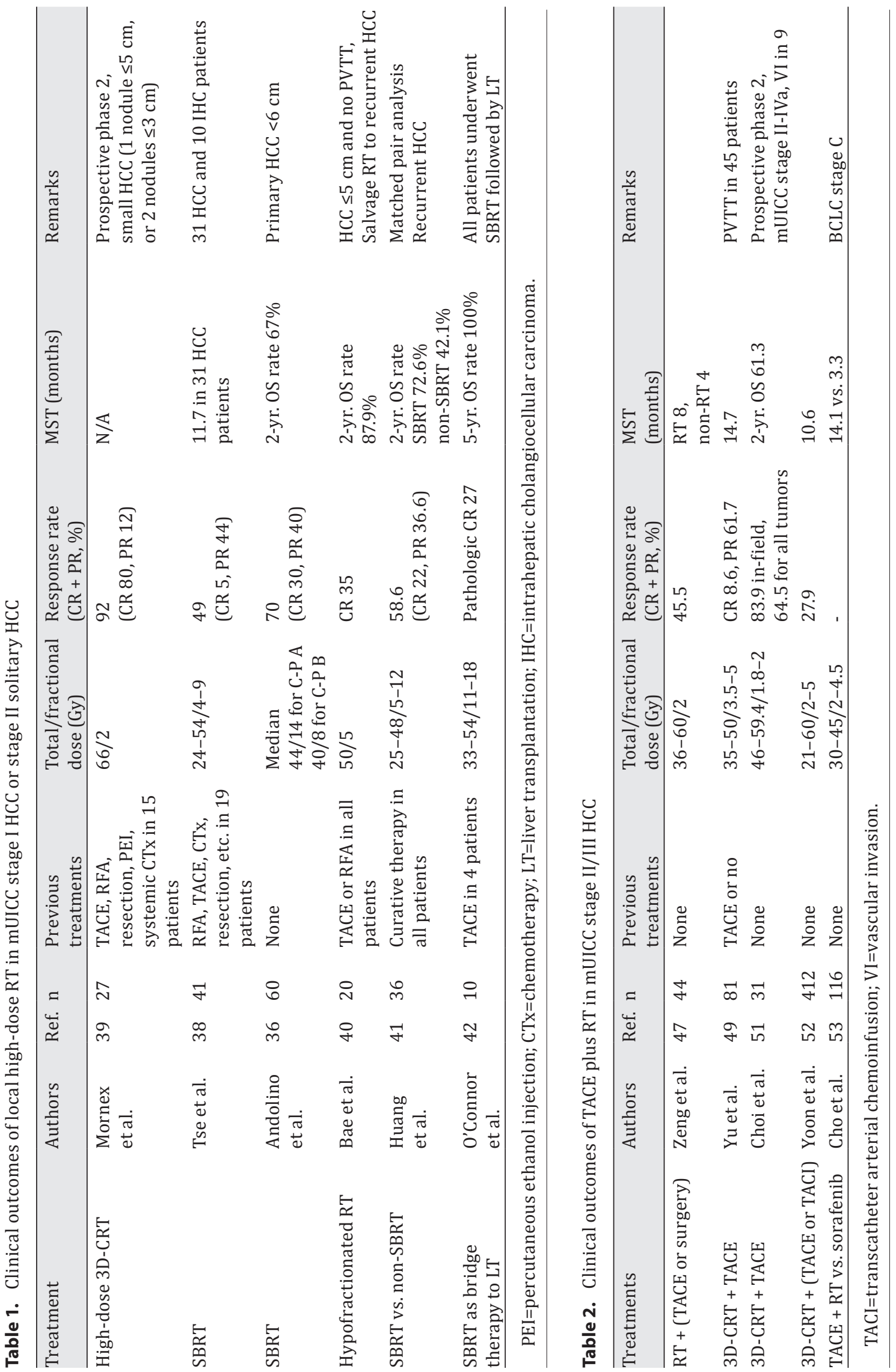
with vascular invasion $[33,55,62-64]$ (table 3 ). The MST of patients who undergo HAICCRT ranges from 11.4 to13.1 months. The PVTT response to HAICCRT indicates significant survival improvement [62], with CR and PR rates of $14 \%$ and $48 \%$, respectively. Moreover, PVTT CR is a significant prognostic factor (HR: 0.445, 95\% CI: $0.205-0.968, p=0.041$ ). The objective responses of both the primary tumor and PVTT are significantly associated with improved survival (median: 16.7 months, $\mathrm{p}=0.002$ ). RT-induced downstaging can allow curative resection to be carried out and provide a curative opportunity for some unresectable liver-confined HCC patients [33]. Among 243 patients treated between 2005 and 2011, 41 (16.9\%) underwent curative resection following HAICCRT. The response rate (CR + PR) was $65.9 \%$, and the downstaging rate was $78 \%$. Patients who underwent curative resection after HAICCRT exhibited significantly higher OS than those who did not (5-year OS: $49.6 \%$ vs. 9.8\%; $\mathrm{p}<0.001$ ). A nationwide cohort study also supports the use of HAICCRT as part of a multimodal approach [64]. After propensity score matching, the HAICCRT group had a significantly better OS (median: 11.4 months) than the non-HAICCRT group (median: 6.6 months, $\mathrm{p}=0.02$ ); multivariate analysis of all patients showed HAICCRT was an independent prognostic factor for OS (non-HAICCRT vs. HAICCRT, HR: 1.48, 95\% CI: 1.11-1.97, p=0.007).

\section{Multimodal Approaches Involving RT for Large, Unresectable HCC ( $\geq 5 \mathrm{~cm}$ )}

Multimodal approaches involving RT can affect outcomes in patients with large, unresectable HCCs. Shim et al. compared TACE followed by RT versus TACE alone or repeated TACE [48] (table 3). The inclusion criteria were as follows: (1) single tumors $\geq 5 \mathrm{~cm}$ in diameter receiving TACE as the primary treatment, and (2) patients with PV invasion exceeding the segmental branch. The response to TACE alone was incomplete in $69.5 \%$ of 105 patients. Of the 73 patients with HCC with an incomplete response to TACE, 38 underwent RT and 35 underwent repeated TACE alone. Comparison of RT following incomplete TACE with TACE alone showed that the addition of RT remedied incomplete necrosis after TACE and significantly increased 2-year OS (TACE alone vs. TACE plus RT, 14\% vs. 37\%, p=0.001). The improvement in survival was greater in patients with large tumors. Two-year survival rates for TACE plus RT versus TACE alone were $63 \%$ and $42 \%$, respectively, for tumors $5-7 \mathrm{~cm}$ in diameter, $50 \%$ and $0 \%$ for tumors $8-10 \mathrm{~cm}$ in diameter, and $17 \%$ and $0 \%$ for tumors $>10 \mathrm{~cm}$ in diameter. HAICCRT followed by hepatic arterial infusion chemotherapy (HAIC) or TACE and RT combination therapy also induced excellent intrahepatic control and improved survival in unresectable very large HCCs ( $\geq 10 \mathrm{~cm}$ ) [65] (table 3). The MSTs of patients with very large HCCs who underwent RT and TACE combination therapy (15.3 months) and HAICCRT (12.8 months) were significantly higher than those of patients undergoing TACE alone (7.5 months) or HAIC alone (8.2 months); the time to intrahepatic progression was also significantly greater in those undergoing HAICCRT or combined RT and TACE compared with the other two groups. Multivariate analysis showed that multimodal approaches, including HAICCRT followed by HAIC and TACE and RT combination therapy, are significant independent prognostic factors that positively affect OS.

\section{Multimodal Approaches Involving RT for Multiple mUICC Stage II/III HCCs}

The role of local RT is more uncertain for multiple intrahepatic HCCs. In a study of 107 patients with multiple intrahepatic HCCs, local RT to the main tumor was beneficial if HCCs external to the RT field were already well controlled by another therapy. Patients with viable intrahepatic tumors external to the RT field showed poorer survival than those without such tumors, suggesting that RT is not effective in these patients [66] (table 3). The combination of HAICCRT to the main tumor with PVTT and TACE to other intrahepatic tumors is effective for advanced HCC with both PVTT and intrahepatic metastasis [67]. Median PFS and OS were 4.5 and 9.8 months, respectively. These findings suggest that local RT administered to the 


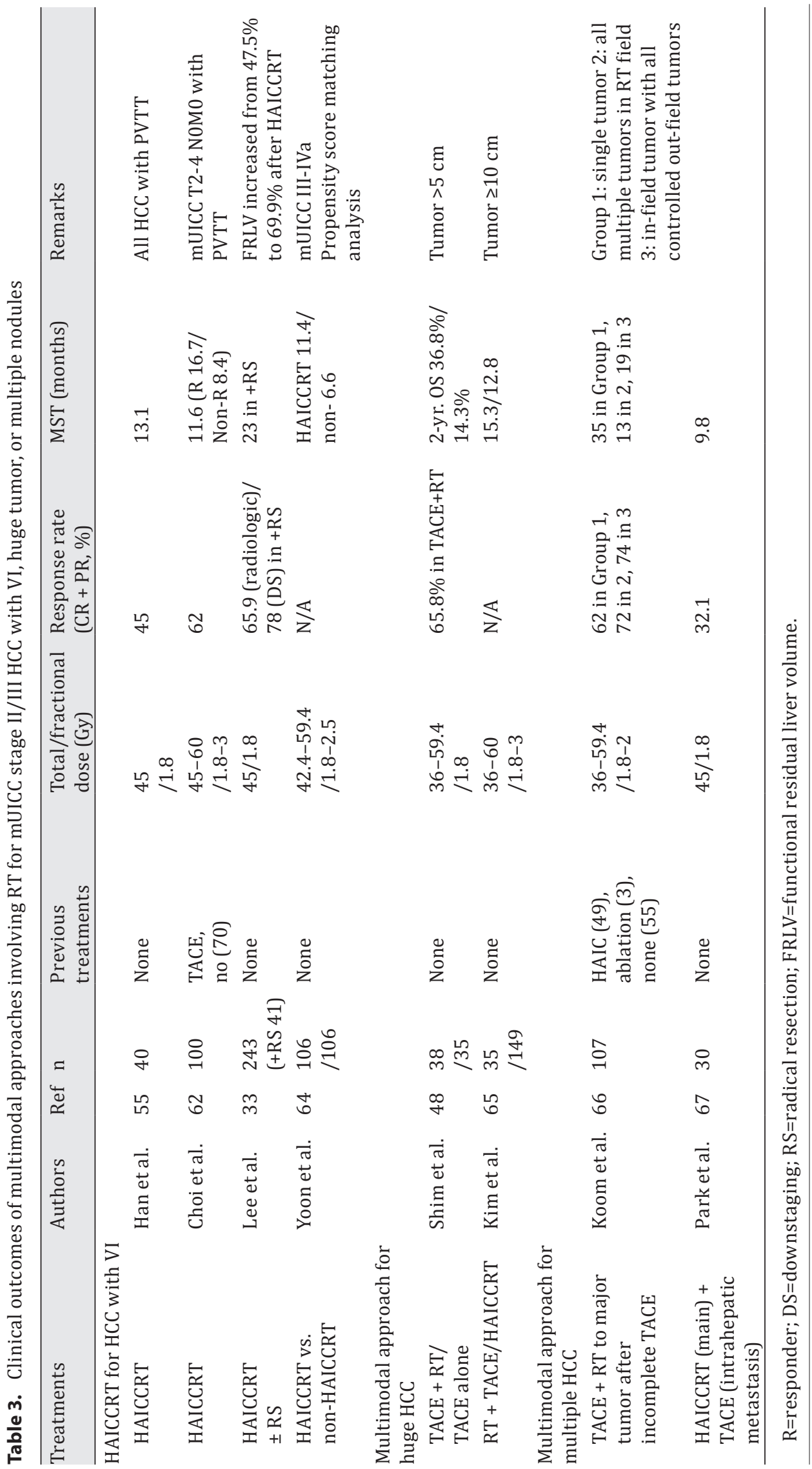


main tumor in a multimodal approach can provide survival benefits for patients with multiple HCCs who have well-controlled intrahepatic tumors external to the RT field. However, a well-designed prospective trial is required for confirmation.

\section{Clinical Trials Investigating the Role of RT in Multimodal Approaches to HCC Treatment}

Clinical trials have investigated the effect and feasibility of RT for HCC. Five phase 3 clinical trials have been registered at ClinicalTrials.gov and are recruiting patients to evaluate the effect of RT in multimodal approaches to HCC treatment (table 4). Trial NCT02125396, titled Adjuvant Radiotherapy Comparing TACE for Curative HCC: a Randomized Controlled Trial, is investigating the efficacy of adjuvant RT compared to adjuvant TACE for HCC patients who have undergone curative surgery and have risk factors for recurrence on pathologic reports. Risk factors for recurrence are tumors $>5 \mathrm{~cm}$, multiple nodules, vascular invasion, the absence of tumor capsule, poorly differentiated tumor, and a narrow resection margin. The primary and secondary endpoints are OS and recurrence rate, respectively. Meanwhile, a randomized phase III trial titled A Trial on SBRT after Incomplete Transcatheter Arterial Embolization (TAE) or TACE versus Exclusive TAE or TACE for Inoperable HCC (NCT02323360) is recruiting participants to compare the effects of SBRT or a new cycle of TACE after incomplete TACE for unresectable HCC. Patients must have a single nodule $\leq 5 \mathrm{~cm}$ or one to three nodules $\leq 3 \mathrm{~cm}$ in diameter after incomplete TACE. The primary endpoint is local control. Two other clinical trials are currently recruiting participants to evaluate the effect of combining RT with sorafenib versus sorafenib alone for advanced HCC. The Randomized Controlled Trial of Proton Beam Radiotherapy+ Sorafenib versus Sorafenib for Patients with Hepatocellular Carcinoma Exceeding San Francisco Criteria (NCT01141478) aims to determine whether proton beam RT plus sorafenib will produce better results than sorafenib alone for treating HCC patients with a tumor burden that exceeds the San Francisco criteria. The other trial, The Radiation Therapy Oncology Group 1112 trial titled Randomized Phase III Study of Sorafenib Versus Stereotactic Body Radiation Therapy Followed by Sorafenib in Hepatocellular Carcinoma (NCT01730937), is currently recruiting participants to compare the effect of SBRT followed by sorafenib with sorafenib alone for primary or recurrent advanced HCC. The primary endpoint of these two clinical trials is OS.

\section{Optimal RT in Multimodal Approaches to HCC Treatment}

\section{Hepatic Functional Reserve}

HCC patients are required to have sufficient hepatic functional reserve before RT. According to the 2014 KLCSG-NCC Korea practice guidelines [10], Child-Pugh class A or B patients are eligible for SBRT and fractionated RT [68]. Yoon et al. investigated whether poor hepatic function can predict radiation-induced hepatotoxicity according to the pre-RT value of the indocyanine green retention rate 15 min after administration (ICG-R15) in patients with HCC treated with RT [69]. The incidences of RILD in patients with ICG-R15 levels $\geq 22 \%$ and $<22 \%$ before RT were $40.7 \%$ and $3.4 \%$, respectively $(\mathrm{p}<0.001)$. Consequently, patients with poor hepatic functional reserve may be vulnerable to radiation-induced hepatic toxicity despite receiving an appropriate RT dose.

HCC patients hoping to undergo RT must meet several conditions to sustain sufficient hepatic functional reserve; these conditions take into account the tumor volume, the irra- 
Table 4. Clinical trials investigating the role of RT in multimodal approaches to HCC treatment

\begin{tabular}{|c|c|c|c|c|c|}
\hline Title & NCT number & $\begin{array}{l}\text { Estimated } \\
\text { enrollment }\end{array}$ & Arms & $\begin{array}{l}\text { Primary } \\
\text { endpoint }\end{array}$ & $\begin{array}{l}\text { Secondary } \\
\text { endpoint }\end{array}$ \\
\hline $\begin{array}{l}\text { Adjuvant Radiotherapy } \\
\text { Comparing TACE for } \\
\text { Curative HCC (ARTC-HCC) }\end{array}$ & NCT02125396 & 150 & $\begin{array}{l}\text { Arm 1: } \\
\text { adjuvant RT } \\
\text { Arm 2: TACE }\end{array}$ & OS & $\begin{array}{l}\text { Recurrence } \\
\text { rate }\end{array}$ \\
\hline $\begin{array}{l}\text { A Trial on SBRT after } \\
\text { Incomplete TAE or TACE } \\
\text { versus Exclusive TAE or } \\
\text { TACE for Treatment of } \\
\text { Inoperable HCC }\end{array}$ & NCT02323360 & 80 & $\begin{array}{l}\text { After TAE or } \\
\text { TACE } \\
\text { Arm 1: SBRT, } \\
\text { Arm 2: TACE }\end{array}$ & $\begin{array}{l}\text { Local } \\
\text { control }\end{array}$ & $\begin{array}{l}\text { OS, PFS, } \\
\text { toxicity }\end{array}$ \\
\hline $\begin{array}{l}\text { Proton Beam Radiotherapy } \\
\text { Plus Sorafenib Versus } \\
\text { Sorafenib for Patients with } \\
\text { Hepatocellular Carcinoma } \\
\text { Exceeding } \\
\text { San Francisco Criteria }\end{array}$ & NCT01141478 & 220 & $\begin{array}{l}\text { Arm 1: sorafenib } \\
\text { Arm 2: proton } \\
\text { beam RT plus } \\
\text { sorafenib }\end{array}$ & OS & $\begin{array}{l}\text { Radiological } \\
\text { progression }\end{array}$ \\
\hline $\begin{array}{l}\text { Sorafenib Tosylate with or } \\
\text { without Stereotactic Body } \\
\text { Radiation Therapy in } \\
\text { Treating Patients with } \\
\text { Liver Cancer }\end{array}$ & NCT01730937 & 368 & $\begin{array}{l}\text { Arm 1: sorafenib } \\
\text { Arm 2: SBRT } \\
\text { plus sorafenib }\end{array}$ & OS & $\begin{array}{l}\text { TTP, PFS, G4 } \\
\text { or } 5 \text { adverse } \\
\text { events, } \\
\text { health-related } \\
\text { quality of life }\end{array}$ \\
\hline
\end{tabular}

TTP=time to progression.

diated liver volume, and dose-volume parameters. According to the 2014 KLCSG-NCC Korea practice guidelines, the tumor volume must be limited to $\leq 70 \%$ of the total liver volume $[14,70]$. The liver volume receiving $\geq 30$ Gy must be constrained to $\leq 60 \%$ of the total liver volume on dose-volume histograms for 3D-RT planning [71]. For SBRT, the normal liver volume receiving a total dose of $<15$ Gy must be $\geq 700 \mathrm{ml}$ or the mean normal liver dose (liver minus gross tumor volume) must be limited to $<28$ Gy in 2-Gy fractions [72, 73]. Several institutions have similarly applied dose-volume histogram parameter-based RT guidelines [74, 75].

\section{Published Dose Fractionation for Each RT Technique}

The dose prescribed for SBRT has been reported as total doses of 30-60 Gy/5-20 Gy per fraction in several studies [15, 16, 31, 36, 40-42, 76]. With 3D-CRT or IMRT, total doses of 21-60 Gy/1.8-5 Gy per fraction have been reported [18, 47, 49, 51, 59, 64, 65, 67, 77].

\section{Optimal RT Strategy according to Tumor Staging}

Until 2014, the NCCN guidelines recommended RT with evidence level 2B for unresectable HCC patients who were not transplant candidates only [8]. The 2015 NCCN version 2.0 guidelines consider locoregional therapies such as ablation, arterially directed therapy, and RT as preferred therapies for patients with unresectable disease and medically inoperable patients [8]. Furthermore, RT is suggested as a preferred treatment for potentially resectable HCC patients who are not amenable to resection or liver transplantation; the evidence level is $2 \mathrm{~B}$.

On the basis of several studies and guidelines, our recommendations for RT for the treatment of HCC are as follows (fig. 1). (1) For single small mUICC stage I/II HCCs without vascular invasion, high-dose RT such as SBRT is an alternative option in patients unsuitable for surgical resection, liver transplantation, RFA, ethanol injection, or TACE. (2) For mUICC stage II/III patients who exhibit an incomplete response to TACE, combination TACE and RT as salvage 


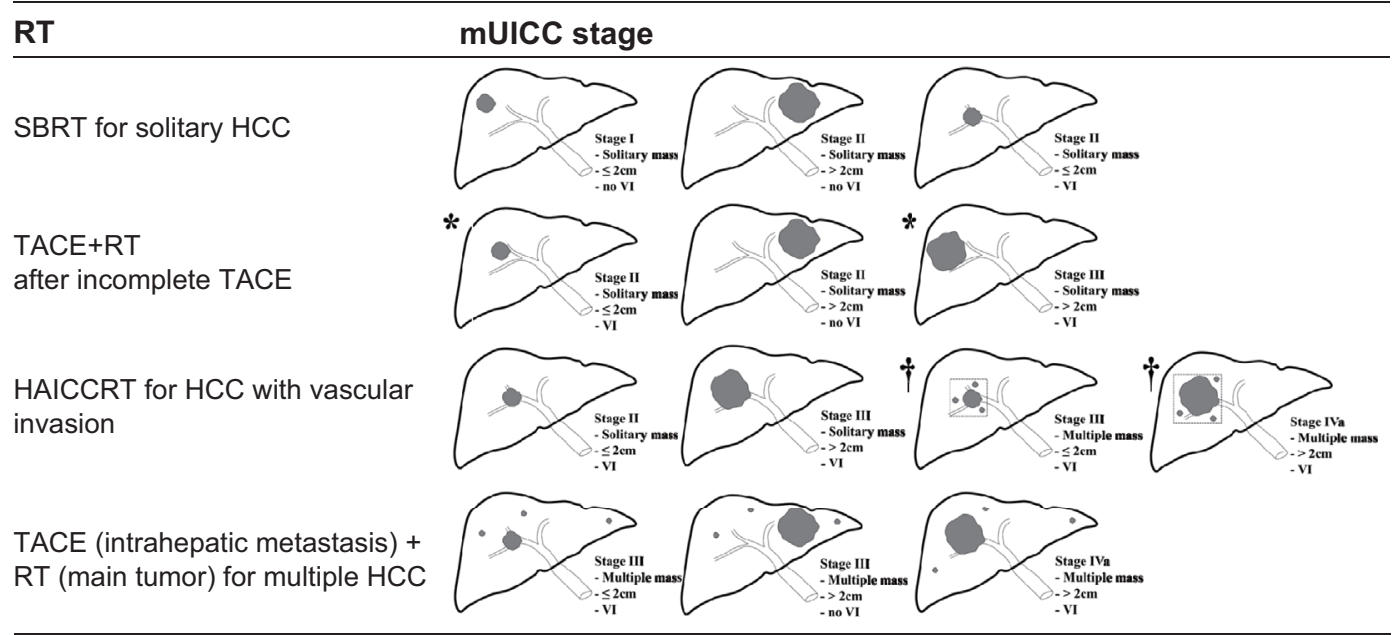

Fig. 1. Suggested application of RT according to the mUICC stage of HCC.

or adjuvant treatment can be considered. (3) For mUICC stage II/III/IVa HCC with vascular invasion or a large diameter, RT can be part of multimodal treatments such as HAICCRT and TACE plus RT; if satellite nodules can be included in the RT field of the major tumor, HAICCRT can be applied for multiple HCCs with vascular invasion. SBRT may also be considered for HCC with vascular invasion. (4) For multiple HCCs in mUICC stage III/IVa patients, a combination of RT for the main tumor and TACE for intrahepatic metastasis can be considered as an alternative treatment.

\section{Summary and Future Directions}

Thanks to recent advances in RT techniques and several studies supporting its clinical applicability, RT has become a feasible therapeutic option for HCC. Multimodal approaches involving RT can be considered for HCC ranging from very early to advanced stages. Highdose ablative RT delivered in a few fractions can be independently curative. A high ablative dose or conventional RT can complement incomplete results of other treatments such as RFA and TACE. Moreover, a combination of systemic agents and RT can be applied. However, additional randomized controlled trials are required to corroborate the role of multimodal approaches involving RT for the treatment of HCC.

\section{Disclosure Statement}

All authors state that there are no conflicts of interest.

\section{References}

1 Belghiti J, Fuks D: Liver resection and transplantation in hepatocellular carcinoma. Liver Cancer 2012;1:71-82.

2 Jihye C, Jinsil S: Application of radiotherapeutic strategies in the BCLC-defined stages of hepatocellular carcinoma. Liver Cancer 2012;1:216-225. 
3 Cervantes A, Chirivella I, Rodriguez-Braun E, Campos S, Navarro S, García Granero E: A multimodality approach to localized rectal cancer. Ann Oncol 2006;17(Suppl 10):x129-x134.

4 Hadziahmetovic M, Shirai K, Chakravarti A: Recent advancements in multimodality treatment of gliomas. Future Oncol 2011;7:1169-1183.

5 Wiegering A, Isbert C, Dietz UA, Kunzmann V, Ackermann S, Kerscher A, Maeder U, Flentje M, Schlegel N, Reibetanz J, Germer CT, Klein I: Multimodal therapy in treatment of rectal cancer is associated with improved survival and reduced local recurrence - a retrospective analysis over two decades. BMC Cancer 2014;14:816.

6 Bruix J, Sherman M, American Association for the Study of Liver Diseases: Management of hepatocellular carcinoma: an update. Hepatology 2011;53:1020-1022.

7 Yang HJ, Lee JH, Lee DH, Yu SJ, Kim YJ, Yoon JH, Kim HC, Lee JM, Chung JW, Yi NJ, Lee KW, Suh KS, Lee HS: Small single-nodule hepatocellular carcinoma: comparison of transarterial chemoembolization, radiofrequency ablation, and hepatic resection by using inverse probability weighting. Radiology 2014;271:909-918.

8 National Comprehensive Cancer Network: NCCN Clinical Practice Guidelines in Oncology, Hepatobiliary Cancers 2015.

9 Park JW: Korean Liver Cancer Study Group and National Cancer Center [Practice guideline for diagnosis and treatment of hepatocellular carcinoma]. Korean J Hepatol 2004;10:88-98.

10 Korean Liver Cancer Study Group (KLCSG) National Cancer Center, Korea (NCC): 2014 Korean Liver Cancer Study Group-National Cancer Center Korea practice guideline for the management of hepatocellular carcinoma. Korean J Radiol 2015;16:465-522.

11 Emami B, Lyman J, Brown A, Coia L, Goitein M, Munzenrider JE, Shank B, Solin LJ, Wesson M: Tolerance of normal tissue to therapeutic irradiation. Int J Radiat Oncol Biol Phys 1991;21:109-122.

12 Dawson LA, Normolle D, Balter JM, McGinn CJ, Lawrence TS, Ten Haken RK: Analysis of radiation-induced liver disease using the Lyman NTCP model. Int J Radiat Oncol Biol Phys 2002;53:810-821.

13 Jackson A, Ten Haken RK, Robertson JM, Kessler ML, Kutcher GJ, Lawrence TS: Analysis of clinical complication data for radiation hepatitis using a parallel architecture model. Int J Radiat Oncol Biol Phys 1995;31:883-891.

14 Dawson LA, Ten Haken RK: Partial volume tolerance of the liver to radiation. Semin Radiat Oncol 2005;15:279-283.

15 Cárdenes HR, Price TR, Perkins SM, Maluccio M, Kwo P, Breen TE, Henderson MA, Schefter TE, Tudor K, Deluca J, Johnstone PA: Phase I feasibility trial of stereotactic body radiation therapy for primary hepatocellular carcinoma. Clin Transl Oncol 2010;12:218-225.

16 Yoon SM, Lim YS, Park MJ, Kim SY, Cho B, Shim JH, Kim KM, Lee HC, Chung YH, Lee YS, Lee SG, Lee YS, Park JH, Kim JH: Stereotactic body radiation therapy as an alternative treatment for small hepatocellular carcinoma. PLoS ONE 2013;8:e79854.

17 Cheng JC, Wu JK, Huang CM, Liu HS, Huang DY, Tsai SY, Cheng SH, Jian JJ, Huang AT: Dosimetric analysis and comparison of three-dimensional conformal radiotherapy and intensity-modulated radiation therapy for patients with hepatocellular carcinoma and radiation-induced liver disease. Int J Radiat Oncol Biol Phys 2003;56:229-234.

18 Yoon HI, Lee IJ, Han KH, Seong J: Improved oncologic outcomes with image-guided intensity-modulated radiation therapy using helical tomotherapy in locally advanced hepatocellular carcinoma. J Cancer Res Clin Oncol 2014;140:1595-1605.

19 Lee IJ, Seong J, Koom WS, Kim YB, Jeon BC, Kim JH, Han KH: Selection of the optimal radiotherapy technique for locally advanced hepatocellular carcinoma. Jpn J Clin Oncol 2011;41:882-889.

20 Blomgren H, Lax I, Näslund I, Svanström R: Stereotactic high dose fraction radiation therapy of extracranial tumors using an accelerator. Clinical experience of the first thirty-one patients. Acta Oncol 1995;34:861870.

21 Loo BW Jr, Chang JY, Dawson LA, Kavanagh BD, Koong AC, Senan S, Timmerman RD: Stereotactic ablative radiotherapy: what's in a name? Pract Radiat Oncol 2011;1:38-39.

22 Potters L, Gaspar LE, Kavanagh B, Galvin JM, Hartford AC, Hevezi JM, Kupelian PA, Mohiden N, Samuels MA, Timmerman R, Tripuraneni P, Vlachaki MT, Xing L, Rosenthal SA, American Society for Therapeutic Radiology and Oncology, American College of Radiology: American Society for Therapeutic Radiology and Oncology (ASTRO) and American College of Radiology (ACR) practice guidelines for image-guided radiation therapy (IGRT). Int J Radiat Oncol Biol Phys 2010;76:319-325.

23 Louis C, Dewas S, Mirabel X, Lacornerie T, Adenis A, Bonodeau F, Lartigau E: Stereotactic radiotherapy of hepatocellular carcinoma: preliminary results. Technol Cancer Res Treat 2010;9:479-487.

24 Choi BO, Choi IB, Jang HS, Kang YN, Jang JS, Bae SH, Yoon SK, Chai GY, Kang KM: Stereotactic body radiation therapy with or without transarterial chemoembolization for patients with primary hepatocellular carcinoma: preliminary analysis. BMC Cancer 2008;8:351.

25 Emami B, Purdy JA, Simpson JR, Harms W, Gerber R, Wippold JF: 3-D conformal radiotherapy in head and neck cancer. The Washington University experience. Front Radiat Ther Oncol 1996;29:207-220.

26 Graham MV, Purdy JA, Emami B, Harms W, Matthews J: 3-D conformal radiotherapy for lung cancer. The Washington University experience. Front Radiat Ther Oncol 1996;29:188-198.

27 Purdy JA: Intensity-modulated radiation therapy. Int J Radiat Oncol Biol Phys 1996;35:845-846.

28 Intensity Modulated Radiation Therapy Collaborative Working Group: Intensity-modulated radiotherapy: current status and issues of interest. Int J Radiat Oncol Biol Phys 2001;51:880-914.

29 Verellen D, De Ridder M, Linthout N, Tournel K, Soete G, Storme G: Innovations in image-guided radiotherapy. Nat Rev Cancer 2007;7:949-960. 
30 Potters L, Kavanagh B, Galvin JM, Hevezi JM, Janjan NA, Larson DA, Mehta MP, Ryu S, Steinberg M, Timmerman R, Welsh JS, Rosenthal SA, American Society for Therapeutic Radiology and Oncology, American College of Radiology: American Society for Therapeutic Radiology and Oncology (ASTRO) and American College of Radiology (ACR) practice guideline for the performance of stereotactic body radiation therapy. Int J Radiat Oncol Biol Phys 2010;76:326-332.

31 Seo YS, Kim MS, Yoo SY, Cho CK, Choi CW, Kim JH, Han CJ, Park SC, Lee BH, Kim YH, Lee DH: Preliminary result of stereotactic body radiotherapy as a local salvage treatment for inoperable hepatocellular carcinoma. J Surg Oncol 2010;102:209-214.

32 Scorsetti M, Comito T, Cozzi L, Clerici E, Tozzi A, Franzese C, Navarria P, Fogliata A, Tomatis S, D’Agostino G, Iftode C, Mancosu P, Ceriani R, Torzilli G: The challenge of inoperable hepatocellular carcinoma (HCC): results of a single-institutional experience on stereotactic body radiation therapy (SBRT). J Cancer Res Clin Oncol 2015;141:1301-1309.

33 Lee HS, Choi GH, Choi JS, Kim KS, Han KH, Seong J, Ahn SH, Kim Y, Park JY, Kim SU, Kim BK: Surgical resection after down-staging of locally advanced hepatocellular carcinoma by localized concurrent chemoradiotherapy. Ann Surg Oncol 2014;21:3646-3653.

34 Ueno S, Tanabe G, Nuruki K, et al: Prognostic performance of the new classification of primary liver cancer of Japan (4th edition) for patients with hepatocellular carcinoma: a validation analysis. Hepatol Res 2002;24:395-403.

35 Liver Cancer Study Group of Japan: [The general rules for the clinical and pathological study of primary liver cancer]. 3rd English edition. Tokyo: Kanehara; 2010.

36 Andolino DL, Johnson CS, Maluccio M, Kwo P, Tector AJ, Zook J, Johnstone PA, Cardenes HR: Stereotactic body radiotherapy for primary hepatocellular carcinoma. Int J Radiat Oncol Biol Phys 2011;81:e447e453.

37 Son SH, Choi BO, Ryu MR, Kang YN, Jang JS, Bae SH, Yoon SK, Choi IB, Kang KM, Jang HS: Stereotactic body radiotherapy for patients with unresectable primary hepatocellular carcinoma: dose-volumetric parameters predicting the hepatic complication. Int J Radiat Oncol Biol Phys 2010;78:1073-1080.

38 Tse RV, Hawkins M, Lockwood G, Kim JJ, Cummings B, Knox J, Sherman M, Dawson LA: Phase I study of individualized stereotactic body radiotherapy for hepatocellular carcinoma and intrahepatic cholangiocarcinoma. J Clin Oncol 2008;26:657-664.

39 Mornex F, Girard N, Beziat C, Kubas A, Khodri M, Trepo C, Merle P: Feasibility and efficacy of high-dose three-dimensional-conformal radiotherapy in cirrhotic patients with small-size hepatocellular carcinoma non-eligible for curative therapies - mature results of the French Phase II RTF-1 trial. Int J Radiat Oncol Biol Phys 2006;66:1152-1158.

40 Bae SH, Park HC, Lim H, Lee JA, Gwak GY, Choi MS, Lee JH, Koh KC, Paik SW, Yoo BC: Salvage treatment with hypofractionated radiotherapy in patients with recurrent small hepatocellular carcinoma. Int J Radiat Oncol Biol Phys 2012;82:e603-e607.

41 Huang WY, Jen YM, Lee MS, Chang LP, Chen CM, Ko KH, Lin KT, Lin JC, Chao HL, Lin CS, Su YF, Fan CY, Chang YW: Stereotactic body radiation therapy in recurrent hepatocellular carcinoma. Int J Radiat Oncol Biol Phys 2012;84:355-361.

42 O'Connor JK, Trotter J, Davis GL, Dempster J, Klintmalm GB, Goldstein RM: Long-term outcomes of stereotactic body radiation therapy in the treatment of hepatocellular cancer as a bridge to transplantation. Liver Transpl 2012;18:949-954.

43 de Lope CR, Tremosini S, Forner A, Reig M, Bruix J: Management of HCC. J Hepatol 2012;56(Suppl 1):S75-S87.

44 Sakurai M, Okamura J, Kuroda C: Transcatheter chemo-embolization effective for treating hepatocellular carcinoma. A histopathologic study. Cancer 1984;54:387-392.

45 Yu YQ, Xu DB, Zhou XD, Lu JZ, Tang ZY, Mack P: Experience with liver resection after hepatic arterial chemoembolization for hepatocellular carcinoma. Cancer 1993;71:62-65.

46 Guo WJ, Yu EX: Evaluation of combined therapy with chemoembolization and irradiation for large hepatocellular carcinoma. Br J Radiol 2000;73:1091-1097.

47 Zeng ZC, Tang ZY, Fan J, Zhou J, Qin LX, Ye SL, Sun HC, Wang BL, Yu Y, Wang JH, Guo W: A comparison of chemoembolization combination with and without radiotherapy for unresectable hepatocellular carcinoma. Cancer J 2004;10:307-316.

48 Shim SJ, Seong J, Han KH, Chon CY, Suh CO, Lee JT: Local radiotherapy as a complement to incomplete transcatheter arterial chemoembolization in locally advanced hepatocellular carcinoma. Liver Int 2005;25:1189-1196.

49 Yu JI, Park HC, Lim H, Park W, Yoo BC, Paik SW, Koh KC, Lee JH: Prognostic index for portal vein tumor thrombosis in patients with hepatocellular carcinoma treated with radiation therapy. J Korean Med Sci 2011;26:1014-1022.

50 Meng MB, Cui YL, Lu Y, She B, Chen Y, Guan YS, Zhang RM: Transcatheter arterial chemoembolization in combination with radiotherapy for unresectable hepatocellular carcinoma: a systematic review and meta-analysis. Radiother Oncol 2009;92:184-194.

51 Choi C, Koom WS, Kim TH, Yoon SM, Kim JH, Lee HS, Nam TK, Seong J: A prospective phase 2 multicenter study for the efficacy of radiation therapy following incomplete transarterial chemoembolization in unresectable hepatocellular carcinoma. Int J Radiat Oncol Biol Phys 2014;90:1051-1060.

52 Yoon SM, Lim YS, Won HJ, Kim JH, Kim KM, Lee HC, Chung YH, Lee YS, Lee SG, Park JH, Suh DJ: Radiotherapy plus transarterial chemoembolization for hepatocellular carcinoma invading the portal vein: longterm patient outcomes. Int J Radiat Oncol Biol Phys 2012;82:2004-2011. 
53 Cho JY, Paik YH, Park HC, Yu JI, Sohn W, Gwak GY, Choi MS, Lee JH, Koh KC, Paik SW, Yoo BC: The feasibility of combined transcatheter arterial chemoembolization and radiotherapy for advanced hepatocellular carcinoma. Liver Int 2014;34:795-801.

54 Lo CH, Huang WY, Lee MS, Lin KT, Lin TP, Chang PY, Fan CY, Jen YM: Stereotactic ablative radiotherapy for unresectable hepatocellular carcinoma patients who failed or were unsuitable for transarterial chemoembolization. Eur J Gastroenterol Hepatol 2014;26:345-352.

55 Han KH, Seong J, Kim JK, Ahn SH, Lee Y, Chon CY: Pilot clinical trial of localized concurrent chemoradiation therapy for locally advanced hepatocellular carcinoma with portal vein thrombosis. Cancer 2008;113:9951003.

56 Kim DY, Park W, Lim DH, Lee JH, Yoo BC, Paik SW, Kho KC, Kim TH, Ahn YC, Huh SJ: Three-dimensional conformal radiotherapy for portal vein thrombosis of hepatocellular carcinoma. Cancer 2005;103:2419-2426.

57 Huang YJ, Hsu HC, Wang CY, Wang CJ, Chen HC, Huang EY, Fang FM, Lu SN: The treatment responses in cases of radiation therapy to portal vein thrombosis in advanced hepatocellular carcinoma. Int J Radiat Oncol Biol Phys 2009;73:1155-1163.

58 Yeh SA, Chen YS, Perng DS: The role of radiotherapy in the treatment of hepatocellular carcinoma with portal vein tumor thrombus. J Radiat Res (Tokyo) 2015;56:325-331.

59 Kim TH, Kim DY, Park JW, Kim YI, Kim SH, Park HS, Lee WJ, Park SJ, Hong EK, Kim CM: Three-dimensional conformal radiotherapy of unresectable hepatocellular carcinoma patients for whom transcatheter arterial chemoembolization was ineffective or unsuitable. Am J Clin Oncol 2006;29:568-575.

60 Zeng ZC, Fan J, Tang ZY, Zhou J, Wang JH, Wang BL, Guo W: Prognostic factors for patients with hepatocellular carcinoma with macroscopic portal vein or inferior vena cava tumor thrombi receiving external-beam radiation therapy. Cancer Sci 2008;99:2510-2517.

61 Kamiyama T, Nakanishi K, Yokoo H, Tahara M, Nakagawa T, Kamachi H, Taguchi H, Shirato H, Matsushita M, Todo S: Efficacy of preoperative radiotherapy to portal vein tumor thrombus in the main trunk or first branch in patients with hepatocellular carcinoma. Int J Clin Oncol 2007;12:363-368.

62 Choi Y, Kim JW, Cha H, Han KH, Seong J: Overall response of both intrahepatic tumor and portal vein tumor thrombosis is a good prognostic factor for hepatocellular carcinoma patients receiving concurrent chemoradiotherapy. J Radiat Res (Tokyo) 2014;55:113-120.

63 Lee IJ, Kim JW, Han KH, Kim JK, Kim KS, Choi JS, Park YN, Seong J: Concurrent chemoradiotherapy shows long-term survival after conversion from locally advanced to resectable hepatocellular carcinoma. Yonsei Med J 2014;55:1489-1497.

64 Yoon HI, Song KJ, Lee IJ, Kim DY, Han KH, Seong J: Clinical benefit of hepatic arterial infusion concurrent chemoradiotherapy in locally advanced hepatocellular carcinoma: a propensity score matching analysis. Cancer Res Treat 2015; [Epub ahead of print]: 10.4143/crt.2014.276.

65 Kim KH, Kim MS, Chang JS, Han KH, Kim Y, Seong J: Therapeutic benefit of radiotherapy in huge $(\geq 10 \mathrm{~cm})$ unresectable hepatocellular carcinoma. Liver Int 2014;34:784-794.

66 Koom WS, Seong J, Han KH, Lee Y, Lee JT: Is local radiotherapy still valuable for patients with multiple intrahepatic hepatocellular carcinomas? Int J Radiat Oncol Biol Phys 2010;77:1433-1440.

67 Park MS, Kim SU, Park JY, Kim Y, Ahn SH, Han KH, Chon CY, Seong J: Combination treatment of localized concurrent chemoradiation therapy and transarterial chemoembolization in locally advanced hepatocellular carcinoma with intrahepatic metastasis. Cancer Chemother Pharmacol 2013;71:165-173.

68 Hawkins MA, Dawson LA: Radiation therapy for hepatocellular carcinoma: from palliation to cure. Cancer 2006;106:1653-1663.

69 Yoon HI, Koom WS, Lee IJ, Jeong K, Chung Y, Kim JK, Lee KS, Han KH, Seong J: The significance of ICG-R15 in predicting hepatic toxicity in patients receiving radiotherapy for hepatocellular carcinoma. Liver Int 2012;32:1165-1171.

70 Seong J, Park HC, Han KH, Chon CY: Clinical results and prognostic factors in radiotherapy for unresectable hepatocellular carcinoma: a retrospective study of 158 patients. Int J Radiat Oncol Biol Phys 2003;55:329-336.

71 Kim TH, Kim DY, Park JW, Kim SH, Choi JI, Kim HB, Lee WJ, Park SJ, Hong EK, Kim CM: Dose-volumetric parameters predicting radiation-induced hepatic toxicity in unresectable hepatocellular carcinoma patients treated with three-dimensional conformal radiotherapy. Int J Radiat Oncol Biol Phys 2007;67:225-231.

72 Schefter TE, Kavanagh BD, Timmerman RD, Cardenes HR, Baron A, Gaspar LE: A phase I trial of stereotactic body radiation therapy (SBRT) for liver metastases. Int J Radiat Oncol Biol Phys 2005;62:1371-1378.

73 Pan CC, Kavanagh BD, Dawson LA, Li XA, Das SK, Miften M, Ten Haken RK: Radiation-associated liver injury. Int J Radiat Oncol Biol Phys 2010;76(Suppl):S94-S100.

74 Lee IJ, Seong J, Shim SJ, Han KH: Radiotherapeutic parameters predictive of liver complications induced by liver tumor radiotherapy. Int J Radiat Oncol Biol Phys 2009;73:154-158.

75 Cheng SH, Lin YM, Chuang VP, Yang PS, Cheng JC, Huang AT, Sung JL: A pilot study of three-dimensional conformal radiotherapy in unresectable hepatocellular carcinoma. J Gastroenterol Hepatol 1999;14:10251033.

76 Kimura T, Aikata H, Takahashi S, Takahashi I, Nishibuchi I, Doi Y, Kenjo M, Murakami Y, Honda Y, Kakizawa H, Awai K, Chayama K, Nagata Y: Stereotactic body radiotherapy for patients with small hepatocellular carcinoma ineligible for resection or ablation therapies. Hepatol Res 2015;45:378-386.

77 Oh D, Lim H, Park HC, Paik SW, Koh KC, Lee JH, Choi MS, Yoo BC, Lim HK, Lee WJ, Rhim H, Shin SW, Park KB Early three-dimensional conformal radiotherapy for patients with unresectable hepatocellular carcinoma after incomplete transcatheter arterial chemoembolization: a prospective evaluation of efficacy and toxicity. Am J Clin Oncol 2010;33:370-375. 